\title{
Application of Advancement Flap After Loose Seton Placement: A Modified Two-Stage Surgical Repair of a Transsphincteric Anal Fistula
}

\author{
Metin Ertem ${ }^{1,2}$, Hakan Gok ${ }^{1}$, Emel Ozveri ${ }^{1}$, Volkan Ozben ${ }^{1}$ \\ ${ }^{1}$ General Surgery Clinic, Kozyatagi Acibadem Hospital, Istanbul, ${ }^{2}$ Department of General Surgery, Istanbul University, Cerrahpasa Medical \\ School, Istanbul, Turkey
}

Purpose: A number of techniques have been described for the treatment of a transsphincteric anal fistula. In this report, we aimed to introduce a relatively new two-stage technique, application of advancement flap after loose seton placement, to present its technical aspects and to document our results.

Methods: Included in this retrospective study were 13 patients (10 males, 3 females) with a mean age of 42 years who underwent a two-stage seton and advancement flap surgery for transsphincteric anal fistula between June 2008 and June 2013. In the first stage, a loose seton was placed in the fistula tract, and in the second stage, which was performed three months later, the internal and external orifices were closed with advancement flaps.

Results: All the patients were discharged on the first postoperative day. The mean follow-up period was 34 months. Only one patient reported anal rigidity and intermittent pain, which was eventually resolved with conservative measures. The mean postoperative Wexner incontinence score was 1 . No recurrence or complications were observed, and no further surgical intervention was required during follow-up.

Conclusion: The two-stage seton and advancement flap technique is very efficient and seems to be a good alternative for the treatment of a transsphincteric anal fistula.

Keywords: Anal fistula; Seton; Flap; Surgery

\section{INTRODUCTION}

Perianal fistula is a very common disease seen in the general population, with a rate of 5.6-12.3/100.000 [1-3]. According to the cryptoglandular hypothesis, this disease arises from an infectious process of the intersphincteric glands $[1,3]$. Generally, fistulectomy is an adequate surgical procedure for the treatment of a sim-

Received: October 6, 2013 - Accepted: November 5, 2013

Correspondence to: Volkan Ozben, M.D.

General Surgery Clinic, Kozyatagi Acibadem Hospital, Inonu cad. Okur sok.

No: 20, Kozyatagi, 34742, Istanbul, Turkey

Tel: +90-216-571-4444, Fax: +90-216-571-4000

E-mail:volkanozben@yahoo.co.uk

(c) 2014 The Korean Society of Coloproctology

This is an open-access article distributed under the terms of the Creative Commons Attribution NonCommercial License (http://creativecommons.org/licenses/by-nc/3.0) which permits unrestricted non-

commercial use, distribution, and reproduction in any medium, provided the original work is properly cited. ple or low transsphincteric fistula. In the presence of a complicated transsphincteric or suprasphincteric fistula, application of advancement flaps, an anal plug, fibrin glue, ligation of the intersphincteric fistula tract (LIFT), radiofrequency ablation, a loose seton, etc. are among the preferred treatment options [4]. The main objective in all these procedures is the treatment of the disease and the prevention of recurrences and anal incontinence. The cutting seton technique, which has been widely used for years, is associated with a high rate of incontinence. Isbister and Al Sanea [5] reported flatus incontinence, semiformed, and formed fecal incontinence rates after surgery of $36 \%, 8.5 \%$, and $2.3 \%$, respectively. In another study, the overall postoperative complication rate was reported to be $63 \%$, with a recurrence rate of $6 \%$ [6]. Because of the high incontinence and recurrence rates seen after the cutting seton technique, the loose seton technique has become the preferred surgical procedure. Because the fistulous tract is kept open in the loose seton technique, local infection can be controlled 
Volume 30, Number 4, 2014

more readily and formation of a more complicated fistula can be prevented. In addition, the anal sphincter function can be better preserved. The purpose of this study is to introduce a relatively new technique, application of an advancement after loose seton placement and present our initial results in the treatment of transsphincteric fistula.

\section{METHODS}

Between June 2006 and June 2013, 54 patients with the diagnosis of a perianal fistula underwent surgery in our general surgery clinics in Kozyatagi Acibadem Hospital and Istanbul University Cerrahpasa Medical Faculty. The procedures used the cutting seton technique in the 14 patients with an intersphincteric fistula, a fistulotomy in the 27 patients with a simple fistula, and a two-stage loose seton technique and advancement flap in the 13 patients with a transsphincteric fistula. Patients with anal fistula due to Crohn's disease were excluded from the study.

Of the 13 patients who underwent the two-stage loose seton and advancement flap technique, 10 were male patients and 3 were female, with a mean age of 42 years (range, 29-59 years). All patients were informed about the procedure, and informed consent was obtained from each patient. The patients' medical records were prospectively entered into a database, and the data were retrospectively reviewed. In all these patients, only one external orifice of the fistula tract was found, and it was located posterolaterally on only one side of the gluteal region. The internal orifice was

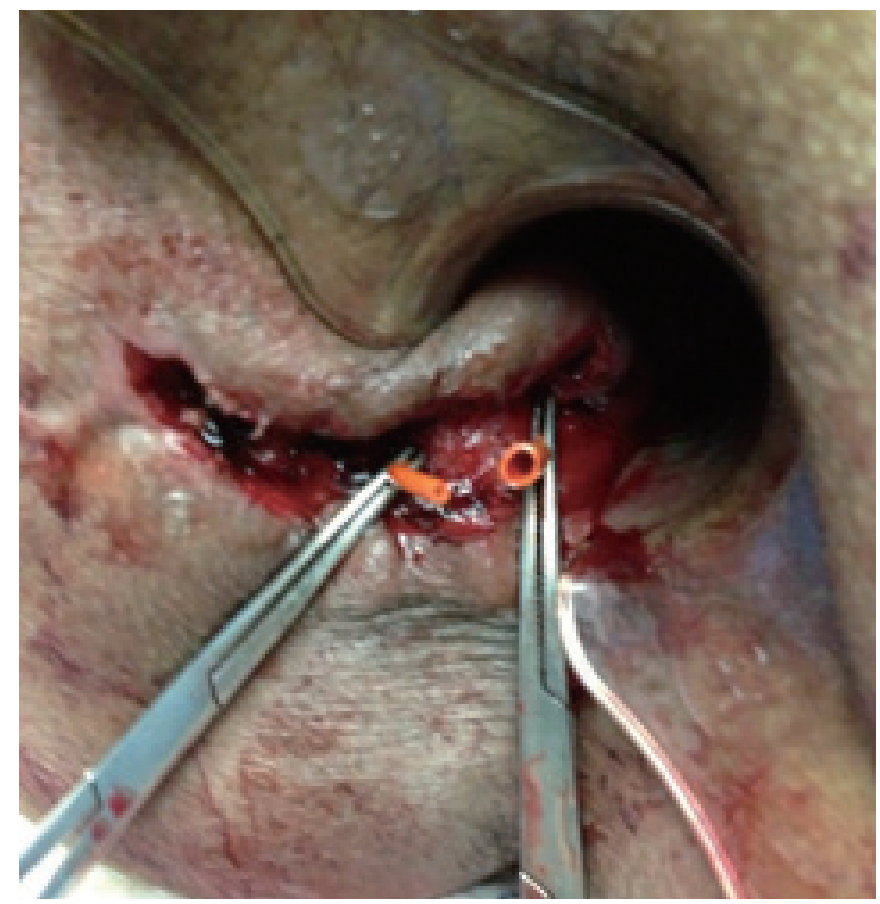

Fig. 1. Placement of loose seton in the transsphincteric fistula tract. localized with pelvic magnetic resonance imaging (MRI) before surgery; then, the two-stage procedure was performed. In the first stage, a loose seton was placed in the fistula tract, and in the second stage, which was performed three months after the first stage, the internal and the external orifices were closed with advancement flaps.

The operation was performed under general anesthesia with the patient in a lithotomy position, and antibiotic prophylaxis was given. In the first stage of the operation, methylene-blue dye was injected from the external orifice of the fistula tract in order to identify the internal orifice; then, a probe was used to trace the tract. Following this, a fistulectomy was done by excising the tract in the gluteal region up to point where the external anal sphincter was located, sparing the sphincter. A loose seton technique was performed with an 8-Fr CH Nelaton silastic tube, encircling both the external and the internal anal sphincters (Fig. 1). One end of the silastic tube was introduced into the other end, and the two ends were tied to each other in order to prevent skin irritation during the postoperative period (Fig. 2). This modification in the seton placement also enabled the seton to move freely by $360^{\circ}$ within the tract.

Three months after the seton placement, the patient was readmitted to the hospital for the second stage of the procedure. During the second stage, the previously placed seton was removed, and in order to close the internal and the external orifices of the fistula tract, respectively, a mucosal advancement flap procedure and a house flap (modified V-Y advancement flap) procedure

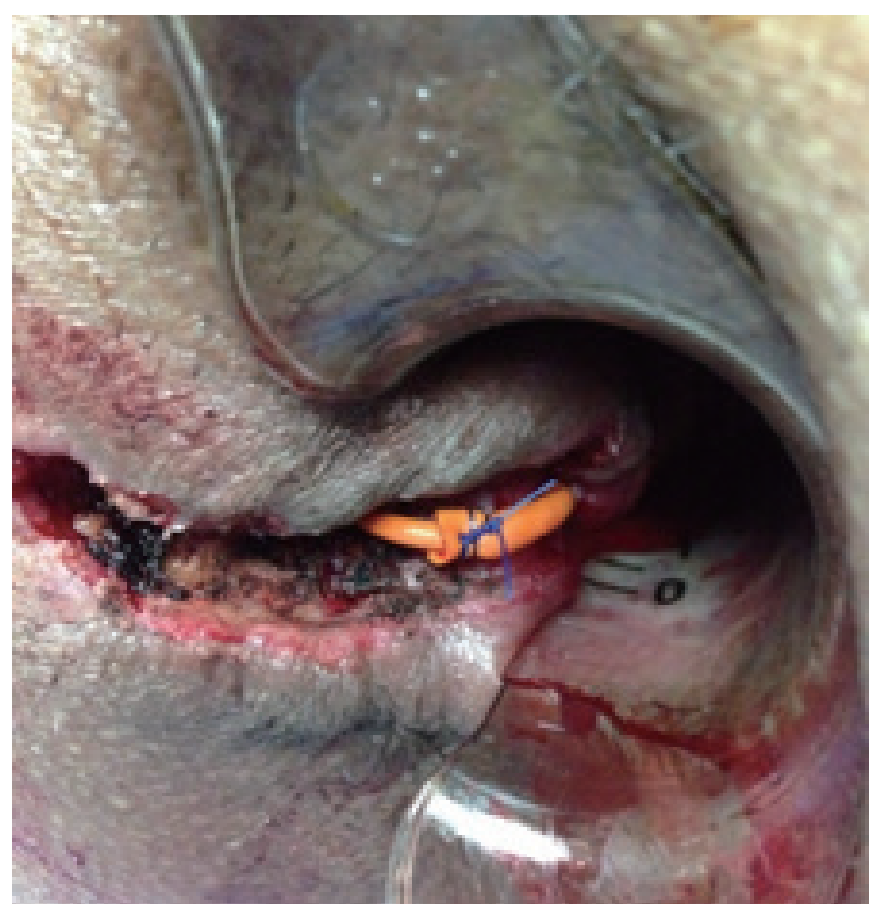

Fig. 2. Appearance of the loose seton after its two ends had been tied to each other. 


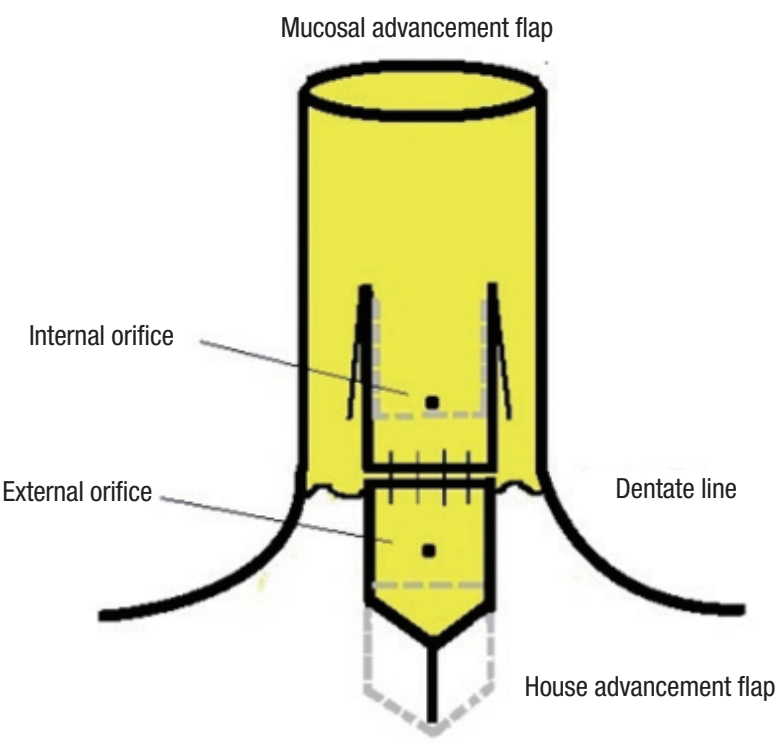

Fig. 3. Schematic illustration of the anatomy of the anal canal after the mucosal and the V-Y advancement flap procedures.

were performed. The two free ends of the flaps were connected to each other at the dentate line with absorbable $3 / 0$ intermittent Vicryl sutures (Figs. 3, 4).

During the postoperative period, antibiotic prophylaxis was continued, and pain control was provided by using nonsteroidal antiinflammatory agents as required. On discharge from the hospital, patients were advised to take a sitz-bath once a day for a week after bowel movements. During follow-up, patients were examined in the clinic in the first, second and fourth postoperative week. After the clinical follow-up, for all the patients, we completed a telephone questionnaire based on the Wexner incontinence scale.

\section{RESULTS}

All the patients were discharged on the first postoperative day. The mean follow-up period was 34 months (range, 6-60 months). No complications, including local sepsis, hemorrhage, ectropion, and intractable pain, were noted during the peri- and the postoperative follow-up periods. Of the 13 patients, only one patient reported anal rigidity and intermittent pain during bowel movements, and these symptoms were gradually resolved with conservative measures. The postoperative mean Wexner incontinence score was 1 . The success rate regarding anal continence was $100 \%$. No recurrence was observed, and no further surgical intervention was required during follow-up.

\section{DISCUSSION}

A perianal fistula is one of the problematic diseases in surgery. Although a number of surgical techniques have been proposed to

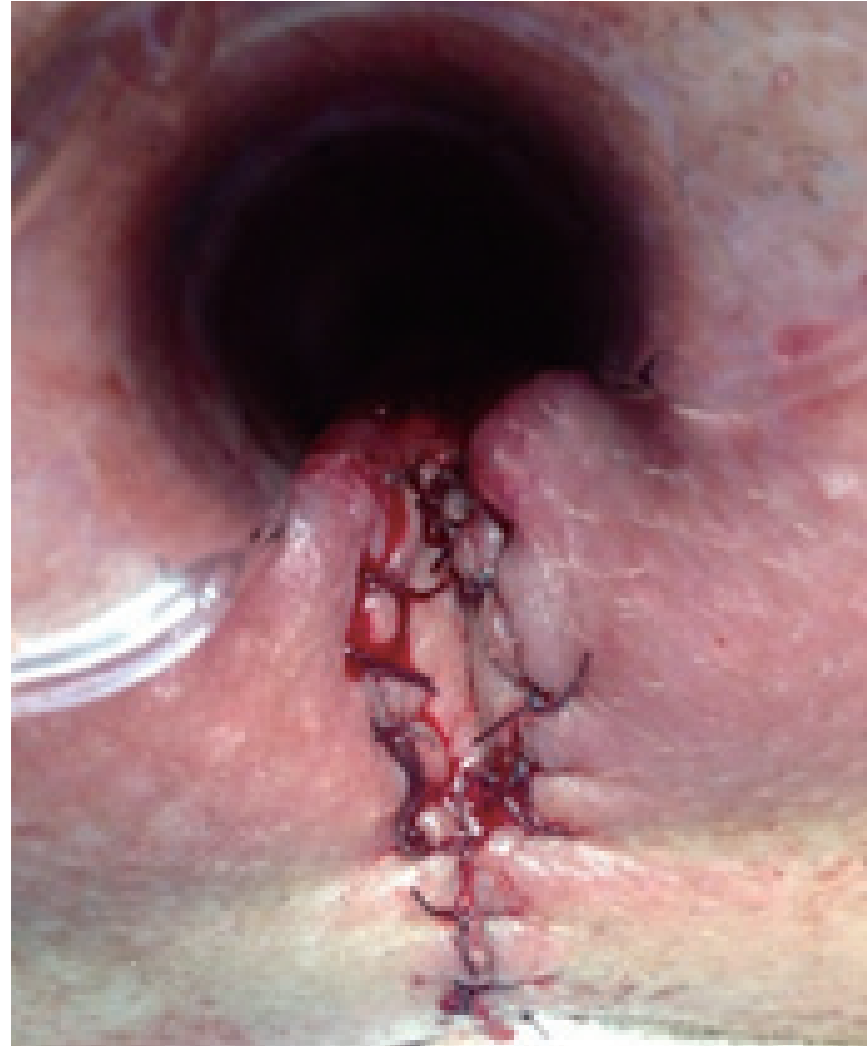

Fig. 4. Postoperative examination of the anal canal.

treat this condition, there is still no single ideal technique for the treatment of this disease. Recently, the LIFT has become a popular procedure $[7,8]$; however, the postoperative results after this procedure have not been convincing. The success rate after the first LIFT procedure has been reported to be $67 \%$, and that after a repeated LIFT has been reported to be $90 \%$ [9]. In several studies, the advancement flap technique has been compared with other techniques. The mucosal advancement flap is a technique that can be used by itself in the treatment of the perianal fistula and has a success rate between $0 \%$ and $83 \%$ [10-12]. One study recommended that ectropion, which is seen after a mucosal advancement flap, could be prevented by using a mucosal V-Y flap, and the success rate was found to be $83 \%$ [12]. In addition to these, the loose seton technique is another option for surgical repair. Eitan et al. [13] reported an incontinence rate of 5\% after loose seton placement. In another study, the incontinence rate was reported to be $0 \%-8 \%$, and only minor complaints were observed in $60 \%$ of the patients $[4,9]$.

There are two important problems in the surgical treatment of an anal fistula, recurrence and incontinence, and these two factors affect the surgical outcome. In their series with 60 patients after a mean follow-up period of 24-months, Galis-Rozen et al. [14] reported a complication, including local sepsis and bleeding, rate of $10 \%$. In this series, fecal incontinence was observed in 4 patients, 
and the recurrence rate was $47 \%$.

In the literature, the success rate after loose seton placement is between $44 \%-78 \%[4,15]$. Success rates, of course, depend on the location of the fistula, and they are reported to be $66 \%$ and $88 \%$ in the presence of anterior and posterior fistulae, respectively [15]. In the presented series with 13 patients, the fistula tract was found to be located posteriorly. Placement of a loose seton by itself does not seem to be a adequate surgical procedure for the treatment of a transsphincteric fistula, which is a rather complicated entity. Because of this, various modifications have been proposed by different authors. Pinedo et al. [4] in their modified loose seton procedure proposed a technique in which the internal orifice was mobilized away from the dentate line by creating a small incision in the internal anal sphincter. This modification keeps the fistula tract dry, which eventually accelerates the healing process. In another study with a different modified loose seton technique, Subhas et al. [16] showed that the seton that was rotated by $360^{\circ}$ around the fistula tract by the patient once a day improved the wound healing process in $75 \%$ of the patients. However, $25 \%$ of the patients did not tolerate this time-demanding treatment. In addition to the seton technique, one of the most commonly performed procedures is the mucosal advancement flap. When performed after the seton placement, the success rate of the mucosal advancement flap is $67 \%-93 \%[10,17]$.

When compared with the LIFT procedure after seton placement, application of an advancement flap has been reported to contribute to a higher success rate (93.5\% vs. 62.5\% ) [18]. Eitan et al. [13] investigated 41 patients who had had a loose seton in place for 3 to 7 months and reported that only one patient had loose stool incontinence, two patients had fecal incontinence, and three patients had mucosal wetting during the late follow-up period. In their series of 11 patients who had undergone a mucosal advancement flap (anoplasty) and internal anal sphincter repair after loose-seton application, Zbar [19] reported that 9 patients experienced successful outcomes.

The time period for the removal of the seton is between 2 and 7 months $[9,13]$. In our series of 13 patients, we removed the seton after 3 months when the second stage of the operation was scheduled for the patients who had recovered from perianal sepsis. In the second stage, the mucosal and anocutaneous advancement flaps were simultaneously performed. During follow-up, which included the Wexner-incontinence-scale-based telephone questionnaire, the success rate was found to be $100 \%$.

We believe that a single fistula tract, a posterior location of the tract and addition of a modified technique after the placement of a loose seton were the main factors that contributed to our high success rate. We also believe that, although leaving the external orifice open and thus functional helped spontaneous drainage, simultaneous closure of both the internal and the external orifices and application of a V-Y house flap improved wound healing and eventually prevented recurrences by vitalizing the poorly perfused tissues around the external orifice [20].
Based on our results, the two-stage seton and advancement flap technique is very efficient and seems to be a good alternative for the treatment of a transsphincteric anal fistula. Further comparative studies with larger series should be done in order to support our findings.

\section{CONFLICT OF INTEREST}

No potential conflict of interest relevant to this article was reported.

\section{REFERENCES}

1. Sainio P. Fistula-in-ano in a defined population: incidence and epidemiological aspects. Ann Chir Gynaecol 1984;73:219-24.

2. Marks CG, Ritchie JK. Anal fistulas at St Mark's Hospital. Br J Surg 1977;64:84-91.

3. van Koperen PJ, Bemelman WA, Bossuyt PM, Gerhards MF, Eijsbouts QA, van Tets WF, et al. The anal fistula plug versus the mucosal advancement flap for the treatment of anorectal fistula (PLUG trial). BMC Surg 2008;8:11.

4. Pinedo MG, Caselli MG, Urrejola SG, Niklitschek LS, Molina PM, Bellolio RF, et al. Modified loose-seton technique for the treatment of complex anal fistulas. Colorectal Dis 2010;12(10 Online): e310-3.

5. Isbister WH, Al Sanea N. The cutting seton: an experience at King Faisal Specialist Hospital. Dis Colon Rectum 2001;44:722-7.

6. Hamalainen KP, Sainio AP. Cutting seton for anal fistulas: high risk of minor control defects. Dis Colon Rectum 1997;40:1443-6.

7. Sirikurnpiboon S, Awapittaya B, Jivapaisarnpong P. Ligation of intersphincteric fistula tract and its modification: Results from treatment of complex fistula. World J Gastrointest Surg 2013;5:123-8.

8. Mushaya C, Bartlett L, Schulze B, Ho YH. Ligation of intersphincteric fistula tract compared with advancement flap for complex anorectal fistulas requiring initial seton drainage. Am J Surg 2012; 204:283-9.

9. Williams JG, MacLeod CA, Rothenberger DA, Goldberg SM. Seton treatment of high anal fistulae. Br J Surg 1991;78:1159-61.

10. Mitalas LE, van Wijk JJ, Gosselink MP, Doornebosch P, Zimmerman DD, Schouten WR. Seton drainage prior to transanal advancement flap repair: useful or not? Int J Colorectal Dis 2010;25: 1499-502.

11. Ortíz H, Marzo J. Endorectal flap advancement repair and fistulectomy for high trans-sphincteric and suprasphincteric fistulas. Br J Surg 2000;87:1680-3.

12. Amin SN, Tierney GM, Lund JN, Armitage NC. V-Y advancement flap for treatment of fistula-in-ano. Dis Colon Rectum 2003; 46:540-3.

13. Eitan A, Koliada M, Bickel A. The use of the loose seton technique as a definitive treatment for recurrent and persistent high trans-sphincteric anal fistulas: a long-term outcome. J Gastrointest Surg 2009;13:1116-9. 


\section{Coloproctology Metin Ertem, et al.}

14. Galis-Rozen E, Tulchinsky H, Rosen A, Eldar S, Rabau M, Stepanski A, et al. Long-term outcome of loose seton for complex anal fistula: a two-centre study of patients with and without Crohn's disease. Colorectal Dis 2010;12:358-62.

15. Kennedy HL, Zegarra JP. Fistulotomy without external sphincter division for high anal fistulae. Br J Surg 1990;77:898-901.

16. Subhas G, Gupta A, Balaraman S, Mittal VK, Pearlman R. Noncutting setons for progressive migration of complex fistula tracts: a new spin on an old technique. Int J Colorectal Dis 2011;26:793-8.

17. Jarrar A, Church J. Advancement flap repair: a good option for complex anorectal fistulas. Dis Colon Rectum 2011;54:1537-41.

18. Tan KK, Alsuwaigh R, Tan AM, Tan IJ, Liu X, Koh DC, et al. To LIFT or to flap? Which surgery to perform following seton insertion for high anal fistula? Dis Colon Rectum 2012;55:1273-7.

19. Zbar AP. Experience with staged mucosal advancement anoplasty for high trans-sphincteric fistula-in-ano. West Indian Med J 2007; 56:446-50.

20. Alver O, Ersoy YE, Aydemir I, Erguney S, Teksoz S, Apaydin B, et al. Use of "house" advancement flap in anorectal diseases. World J Surg 2008;32:2281-6. 